situation is the garden of the north of England. Bofore the appearance of the cholers, there was a stout fight for the Public Health Act, and the obstructives were beaten. Some of the medical men opposed the introduction of the act. Mr. Fairbridge, surgeon, has died at Hexham. There are thirteen deaths in that town. The cholers has visited nearly all the villages by the side of the Tyne. There have been four deaths at Howdon and Willington; four at Walker; two at Carville; and several at the Felling. A very interesting and reassuring fact was related to me this morning by a gentleman from Jarrow, a considerable manufacturing village by the side of the Tyne. An old woman who had been to Newcastle and got rather tipsy, on reaching the village ate some half-cooked herring, was attacked, and died after a short illness. Her husband died a few days after. A board of health was immediately formed, under the presidency of the resident clergyman, a " house to house" visitation was instituted, nuisances were removed, etc.; and though there have been between two and threc hundred cases of diarrhcea (promptly attended to by the medical officers), there has not been it single death, except those of the two old persons mentioned

"The epidemic has been very fatal in a village named Whorlton, near Morpeth. Morpeth seems to have escaped.' (From the Times.)

Brighton, Otwher 1553.

\section{CASE OF POISONING BY CREASOTE; WITH REMARKS.}

By J. D. JEFFERY, Esq., Surgeon.

Case. August 29, 1853, I was called up in the night to see Mrs. B., her husband informing me that "she was in a very strange way, and he thought she was dying."

I found a young woman about twenty-four years of age, in bed. She was insensible; her countenance very pale; frothing at the mouth; pupil quite dilated; pulse regular, rather full, about 80 ; the circulation seemed undisturbed. Every few minutes there was violent urging, nothing but saliva resulting. The stomach had been emptied by vomiting before I came. She had apparently severe paroxysms of pain on the right side of the face, to which she violently applied her hand; then again became prostrate. Her breath smelt strongly of creasote. A molar tooth on the right side of the lower jaw had a large cavity in it.

I endearoured to rouse her by washing the face and temples with cold vinegar and water; and, as the paroxysmis of pain seemed referrible to the liseased tooth, I fetched an instrument and removed it. She seemed scarcely to feel the operation; but the pain, after a short time, appeared to have left her. In the course of an hour she improved, and became partially sensible.

I administered nothing but a mixture of sesquicarbonate of soda and water. The next morning I found her better, but pale and weak; the pupils of the eyes were still much dilated, and vision was imperfect, which continued for several days.

The patient's own account of the matter and of her sensations, which I took down on her recovery, perhajs may not be uninteresting :-

"Whilst in the act of putting a piece of lint saturated with creasote into my tooth, it slipped, and I accidentally swallowed it. In a few minutes (much less than a quarter of an hour), I felt myself going very low. My eyesight went from me; giddiness came on; and everything looked of a dark blue, even the candles, my husband, and everything. I felt a dreadful burning at my chest. I wanted water to quench the burning at my lungs. I vomited, and brought up the piece of lint with some food. I had great pain at the front of my head, and felt numbed all over. The pain at my chest continued, and my eyesight was imperfect for three or four days. I did not see plain until Friday (Sept. 2nd). I did not know my tooth had been taken out."
I think it right to place this case on record. I am not acquainted with a similar one. I should think there could not have been more than five or six drops of creasote on the lint.

I mentioned this case to Dr. Cormack soon after its occurrence, when he observed that the case was remarkable from the characteristic effects of poisoning by creasote having been produced by a dose not much larger than he was in the nabit of prescribing with great adrantage in cases of choleraic serous purging. I find upon referring to Dr. Cormack's account of experiments which he performed on animals in 1836 , with creasote, the following remarks by that gentleman:-

"From all these experiments, the poisonous effects of creasote appear to bear a very striking resemblance to those of prussic acid. Like the latter, creasote acts toxicologically, either by stopping the heart, or by directly affecting the brain alone-just as the dose may be larger or smaller, or according to the manner in which the substauces are introduced into the system. Another very striking point of resemblance between prussic acid and creasote, is the remarkable and almost specific power which they both posscss of arresting vomiting, especially if it be unconnected with organic disease." (Cormack on ('reasote, p. 79.)

In another part of the same work, Dr. Cormack remarks : "In medicine, creasote may be used with great advantage as a sedative or anodyne. To produce such effects, it is given in diseases of the heart, pulmonary complaints, vomiting, and to allay the pain of cancer, etc. A patient under Dr. Shortt, in the Royal infirmary of Edinburgh, afflicted with cancer of the stomach, derived relief from pain in ten minutes after taking a dose of fifteen drops. When its sedative or anodyne action is wished speedily, the object is best attained by inhaling its rapours." (p. 93.)

From the above extracts, and from the fact of my patient not knowing when her tooth was taken out, clear evidence is afforded of the ancusthetic powers of creasote. It may be remarked that chloroform, the popular anxithetic agent of the dny, is, like creasote and prussic acid, one of the most efficient remedies for vomiting: and that the medicinal as well as the poisonous effects of these three agents possess many striking resemblances.

Iowesmore House, Horecster, Oct. 1\%, 1853.

\section{ANOTHLR SINGULAR CASE OF ALOPECIA.}

\section{By GEORGE SELWYN MORRIS, Fiq.}

IT may be interesting to Dr. Barclay's readers in the last. number of the Aswionatios Jouknat (p. 902), to hear of another singular instance of complete alopecia; and as I have a case of precisely the same nature, I subjoin the following notes.

S. A. W. is a young woman aged 20 , residing in this place. Her parents, so far as I can discover, were free from syphilis and scrofula, and were in all respects perfectly healthy people. S. A. W. has not a particle of hair on any part of her hody. I have examined her all over; and have only been able to find a slight appearance of down on certain purts of her skin. She began to lose her hair, without any assignable causc, when between cight and nine years of are. She tells me that her sister, a child between six and seven years old, is in exactly the same predicament.

I have not yet commenced the treatinent; but my present intention is to follow the plan which Dr. Barclay adopted in his case.

Sydenhais, Kent, October $1 \%, 1 \times 53$.

[Another case of complete alopecia reached us as we were going to press. E.D.] 